\title{
Population dynamics of coastal forests of Macrocystis pyrifera in Puerto Toro, Isla Navarino, Southern Chile
}

\author{
B. Santelices and F. P. Ojeda \\ Departamento de Biología Ambiental y de Poblaciones, Facultad de Ciencias Biológicas, Pontifícia Universidad Católica de \\ Chile, Casilla 114-D, Santiago, Chile
}

\begin{abstract}
No clear idea exists on the roles of disturbance, competition and grazing as structuring agents of forests of Macrocystis pyrifera plants in southern South America. Yet, these beds can be used to test specific ecological predictions gathered in geographically separated but physiognomically similar communities in the northern hemisphere. This study evaluates the validity of some of these predictions as they relate to the role of ecological factors regulating distributional patterns of a coastal population ( 40 to $50 \mathrm{~m}$ wide) of $M$. pyrifera in Puerto Toro, Navarino Island, southern Chile. Morphometric studies indicate statistically significant correlations between different parts of the plants so that plant length can be predicted from almost any holdfast dimension. Densities of juveniles of $M$. pyrifera across the belt are inversely correlated with densities of adult plants. Inter-plant distances increase significantly with plant sizes suggesting a density-dependent regulation of plant distribution within the belt. Removal of the floating canopy indeed allows for recruitment of juveniles inside the forest and results in significant changes of inter-plant distances. Experimental removal of Lessonia vadosa at the shallower end of the belt allows $M$. pyrifera to extend further into shallower water. Transplanting experiments indicate the deeper end of the belt to be set primarily by substratum availability. The $M$. pyrifera populations in Puerto Toro thus show a similar growth and reproduction strategy as those described for the North Pacific Ocean. The obviously different climatic and biological conditions have notorious effects only on plant sizes and production rates.
\end{abstract}

\section{INTRODUCTION}

In contrast with the situation in the north Pacific, giant kelp forests from southern South America have been studied only occasionally (Kühnemann, 1970; Dayton et al., 1973; Barrales and Lobban, 1975). Field experimental work in these forests has only been done by Dayton (1974) but with limited results due to climatic and logistic difficulties. Nevertheless the forests from southern South America can serve to test specific ecological predictions gathered in geographically separated but physiognomically similar communities in the northern hemisphere. The present study evaluates the validity of some of these predictions as they relate to the role of ecological factors regulating the distributional patterns of a coastal population of $\mathrm{Ma}$ crocystis pyrifera.

Information gathered especially in the north Pacific points to the effects of different, and often opposing sets of factors as structuring agents of the Macrocystis pyrifera communities. Forests from various geographically different areas often are described as zoned between upper and lower bands of vegetation (McLean, 1962; Neushul, 1965; Quast, 1968; North, 1971, 1972; Foster, 1975) and interspecific interference might have a role setting the upper and lower extent of these forests. On the other hand, grazing, storminess and intraspecific competition have been described as important structuring agents of the M. pyrifera communities. Grazing, especially by sea urchins, has been indicated to clear whole areas of kelp and subsequently prevent reforestation of barren areas (Aleem, 1956, 1973; North, 1959, 1961; McLean, 1962; Leighton et al., 1965; Neushul, 1965; Chapman, 1981). Biological or physical parameters affecting sea-urchin grazing activities therefore often result in sharp changes in kelp densities and sizes (North and Pearse, 1970; Lowry and Pearse, 1973; Estes and Palmisano, 1974; Breen and Mann, 1976; Mattison et al., 1977; Pearse and Hines, 1979; Duggins, 1980, 1981; Bernstein et al. 
1981). In southern California, however, Rosenthal et al. (1974) found that storms and strong surge could produce kelp detachment, entanglement of drifting plants, and eventually clear whole areas which later showed increased juvenile settlement. In these forests interspecific competition for light coupled with storminess would appear as a most important structuring agent.

In southern South America no clear idea exists on the roles of grazers, storms and competition as structuring agents of kelp forest communities. Some kelp beds of southern Chile and Argentina appear to be removed completely by storminess every 3 to 4 y (Dayton, 1974; Barrales and Lobban, 1975). The shallow end of the population of Macrocystis pyrifera in southern South America is often zoned below a band of Lessonia vadosa while the deepest end seems limited by availability of hard substratum. Some authors have remarked on the absence of large and abundant sea urchin populations in the forests of $M$. pyrifera of Chubut, Puerto Deseado (Barrales and Lobban, 1975) but others (Dayton, 1974) have been so impressed by the abundance of sea urchins in areas of southern Chile as to suggest that Loxechinus albus was probably overexploiting the algal beds. In this study we test the effects of 3 sets of ecological factors in the distribution and organization of the $M$. pyrifera populations. We tested the possibility of competitive exclusion of $M$. pyrifera by $L$. vadosa by removing specimens of $L$. vadosa at the upper side of the giant kelp forest. By transplanting plants of $M$. pyrifera we examined whether plants could survive in water deeper than they normally grow providing adequate substratum. Moreover, by removal of the floating canopy of adult $M$. pyrifera individuals we tested for the effects of interspecific interference on density and distribution patterns of the $M$. pyrifera plants. Experimental testing of sea-urchin grazing effects on recruitment of juveniles of $M$. pyrifera in the same kelp bed has been reported elsewhere (Castilla and Moreno, 1982).

\section{MATERIALS AND METHODS}

\section{Study site}

An exploratory survey was conducted among the islands in the Beagle Channel and Nassau Bay (Fig. 1) to select the study site in the austral summer of 1978 (January). In the area, the forests of Macrocystis pyrifera extend as narrow coastal belts 50 to $100 \mathrm{~m}$ wide surrounding the sheltered and semi-sheltered sides of the islands. The belt normally starts 1 to $2 \mathrm{~m}$ below the low limit of spring tides and extends down to 10 to $15 \mathrm{~m}$. Puerto Toro, on the west side of Navarino Island, appeared as a rather typical though somewhat pro-

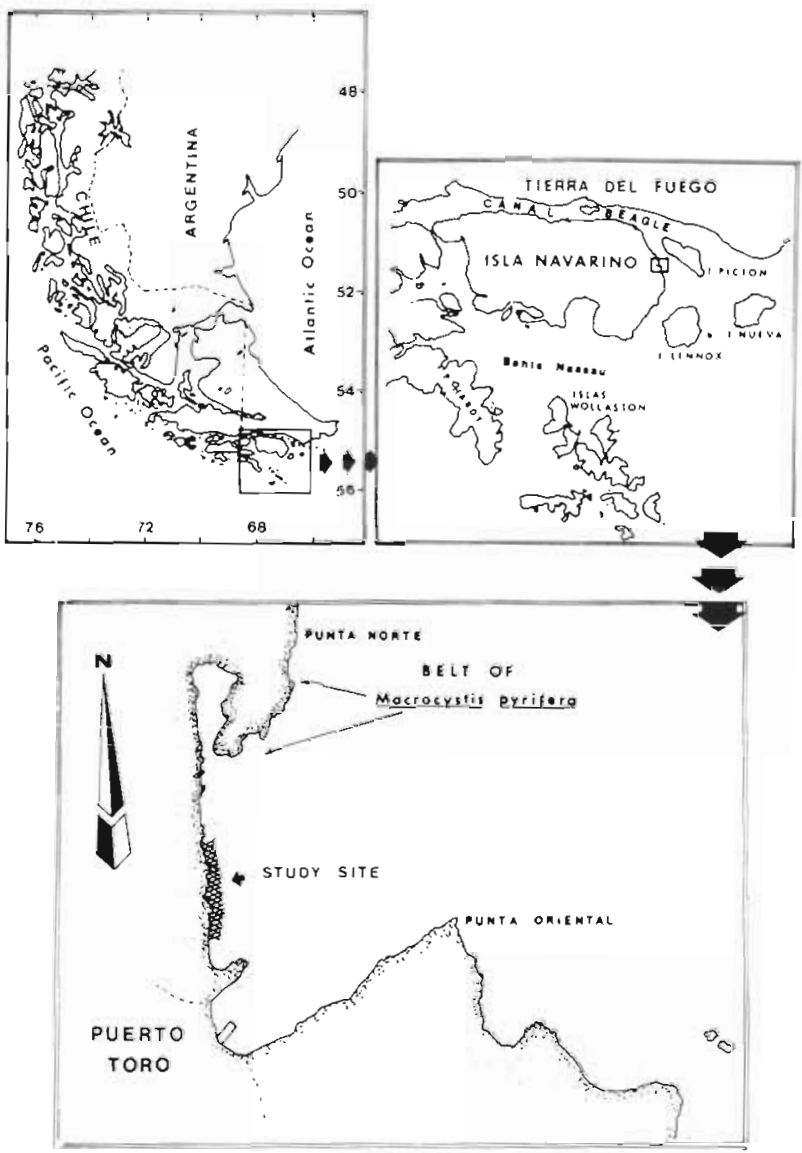

Fig. 1. Study site

tected bay in the area, with a 30-50 m wide coastal $M$. pyrifera belt. In addition, Puerto Toro was the only community on the island (about 30 people) which could provide us with facilities to stay during field work.

Puerto Toro was visited again in August and October 1979 and January, April, May and July 1980. Each trip lasted about $18 \mathrm{~d}$ with not less than $13 \mathrm{~d}$ of effective field work each time. The first trip in August 1979 was devoted entirely to describing the algal bed, measuring abiotic factors and selecting the experimental study sites. Successive trips were oriented to experimental manipulation of several factors expected to have an effect on the distributional pattern of the populations of Macrocystis pyrifera.

\section{Morphometric and distributional studies}

To test for intraspecific competitive interference in the distributional pattern of Macrocystis pyrifera populations we first studied morphometric relationships in a representative number of individuals gathered at various depths across the bed. Then we measured densities and inter-plant distances across the bed and related 
these values to key morphological characters (e.g. holdfast diameter or thallus length). Finally we evaluated changes in interplant distance following canopy removal.

Morphometric relationships were studied in a sample of 70 complete individuals, each haphazardly located by 2 SCUBA divers from a $10 \mathrm{~m}$ wide transect running across the kelp forest. By using an iron bar, each plant was carefully detached from the substratum, numbered in the holdfast, and its depth, the substratum and position recorded. The plants were transported by boat to the beach where each was measured with respect to the longest and shortest holdfast diameter, holdfast height and wet weight, total number of stipes, total stipe length, number of blades along a given stipe and total wet weight of fronds. Holdfast volume was later added to the analysis using the formula $v=\pi a b h / 3$ which assumes that the holdfast morphology approaches an eliptic cone (Ghelardi, 1971), and where $\mathrm{v}=$ holdfast volume; a and $b=$ ratios of the largest and shortest holdfast diameter respectively; and $\mathrm{h}=$ holdfast height.

Measurements on plant densities and distribution patterns were performed across 4 transects. Each transect extended from the shallower to the deeper end of the bed, was $5 \mathrm{~m}$ wide and separated from the next by a $10 \mathrm{~m}$ distance. Measurements along each transect included number of juveniles (defined as individuals less than $1 \mathrm{~m}$ tall) and adults of Macrocystis pyrifera, holdfast dimensions of each individual, nearest neighbour distance and depth and type of substratum. All measurements were performed in October 1979 and repeated in January and April 1980.

Preliminary observations on the Macrocystis pyrifera forest indicated a number of plants to be constantly removed by water movement in spite of the sheltered habitat where they occurred. In order to know if differential removal of a given size was occurring in the bed, a total of 76 holdfasts of plants freshly cast ashore were measured in September and November 1979 and in April 1980. In January and July 1980 no holdfasts were found among the drifted thalli. Relative frequency of small (holdfast less than $5 \mathrm{~cm}$ high) and large plants found among the attached and drift populations were compared using $2 \times 2$ chi square table. Holdfast less than $5 \mathrm{~cm}$ high belong to plants less than $5 \mathrm{~m}$ long and therefore still unable to reach the water surface.

\section{Experimental treatments}

The upper limit of the Macrocystis pyrifera belt appeared sharply bounded below a seemingly monospecific belt of Lessonia vadosa. To test the role of interspecific competition in determining this bound- ary, four $3 \times 4 \mathrm{~m}$ experimental plots were delimited in the boundary area ( 1 to $2 \mathrm{~m}$ depth), each separated from the other by $2 \mathrm{~m}$ distance. In the first plot (Plot $\mathrm{A}$ ) all individuals of $L$. vadosa were removed ( 16 plants of $130 \pm 12 \mathrm{~cm}$ long). Eight juveniles (less than $1 \mathrm{~m}$ long) of $M$. pyrifera found in this plot were left untouched. In the second quadrat (Plot B) all 18 plants of L. vadosa and all individuals of $M$. pyrifera (three $50 \mathrm{~cm}$ long plants) were removed. In the third plot (Plot C), all 17 adult individuals of $L$. vadosa were left untouched but we removed all individuals of $M$. pyrifera (five 45 to 50 $\mathrm{cm}$ long plants). The fourth quadrat (Plot D) was left undisturbed ( 7 juveniles of $M$. pyrifera and 17 adult plants of $L$. vadosa). The effects of these treatments on the distribution of $M$. pyrifera and $L$. vadosa were evaluated 6 mo later (May, 1980), counting and measuring all specimens of both species found in the plots.

To test for the possible limiting effect of substrate on the growth and distribution of Macrocystis pyrifera at the deeper end of the belt, in January 1980, 13 plants ranging from 62 to $150 \mathrm{~cm}$ long were attached by the holdfast every $1 \mathrm{~m}$ to a $20 \mathrm{~m}$ long metalic chain. The longest stipe of each plant was tagged and measured and the chain was then placed $50 \mathrm{~m}$ further beyond the seaward edge of the $M$. pyrifera bed, at a depth of about $12 \mathrm{~m}$ and on muddy substratum. The stipes were measured again in May and July 1980.

To test for the effects of canopy removal on distribution of juvenile kelp plants, a $5 \mathrm{~m}$ wide transect was set across the Macrocystis pyrifera bed in November 1979. The canopy was cut down to $1 \mathrm{~m}$ below the water level during low tide. A total of $950 \mathrm{~kg}$ of wet biomass were gathered in the $250 \mathrm{~m}^{2}$ area. A similar belt transect was delimited in an area $10 \mathrm{~m}$ away but the canopy was not removed. Removal of $M$. pyrifera canopy was repeated in the experimental area in January and May 1980 in order to eliminate the growth of $M$. pyrifera which had occurred since the last removal (198.5 and $325.0 \mathrm{~kg}$ respectively). In July 1980, juvenile density and population patterns of distribution were measured in the removal and non-removal area.

\section{RESULTS}

\section{Structure of the Macrocystis pyrifera belt}

The belt of Macrocystis pyrifera in Puerto Toro Bay, Isla Navarino, was 40 to $50 \mathrm{~m}$ wide and extended from 0.5 to $1 \mathrm{~m}$ below low water level down to 8 to $10 \mathrm{~m}$. A transectional view across the bed (Fig. 2) shows its shallower end to abut a seemingly monospecific, 1 to $2 \mathrm{~m}$ wide belt of Lessonia vadosa Searles. The next $10 \mathrm{~m}$ of bed were characterized by small-sized, densely 


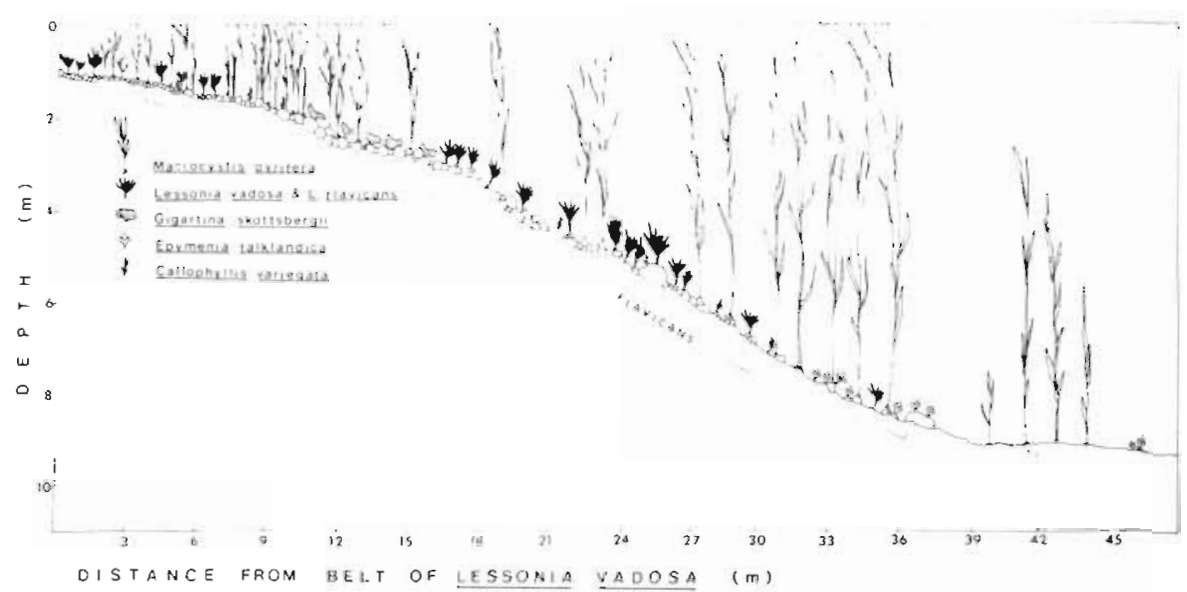

Fig. 2. Transectional view of coastal Macrocystis pyrifera belt at Puerto Toro, Navarino Island

packed individuals of $M$. pyrifera living on consolidated rocky substrate or boulders larger than $30 \mathrm{~cm}$ of diameter. The understory vegetation in this zone was mostly calcareous crustose and sparsely scattered individuals of Gigartina skottsbergii. Individuals of $M$. pyrifera and their inter-plant distances became increasingly larger with increasingly greater depths (down to $6 \mathrm{~m}$, approximately 30 to $40 \mathrm{~m}$ of lineal distance from the border of $L$. vadosa). In this part of the bed understory vegetation showed a clear vertical stratification with a second canopy represented by 1 to $2 \mathrm{~m}$ long individuals of L. flavicans and a third stratum mostly formed by G. skottsbergii, scattered individuals of Epymenia falklandica and filamentous algae. Beyond $6 \mathrm{~m}$, the substratum was soft, with small-sized boulders and pebbles. The distribution of $M$. pyrifera here was interrupted and small-sized plants were found on the larger boulders. The understory vegetation was represented mainly by sparsely scattered individuals of L. flavicans, E. falklandica and filamentous green and brown algae. Beyond $8 \mathrm{~m}$, the substratum was muddy and no vegetation was observed. In some areas, however, consolidated rocky substratum was found down to $15 \mathrm{~m}$. At these depths the $M$. pyrifera plants were bordered by a dense stand of $L$. flavicans.

Surface-water temperature recorded in the area ranged from 5 to $6^{\circ} \mathrm{C}$ in winter (July-August) to 8 to $9^{\circ} \mathrm{C}$ in summer and early fall (January-April). Bottomwater temperature in the bed was normally 1 to $2{ }^{\circ} \mathrm{C}$ less than surface water. Surface water irradiance measured on a sunny day of May, 1980 registered $480 \mu \mathrm{E}$ $\mathrm{m}^{-2} \mathrm{~s}^{-1}$. The surface value was reduced to $150 \mu \mathrm{E} \mathrm{m}^{-2} \mathrm{~s}^{-1}$ in the first meter of water and to $32 \mu \mathrm{E} \mathrm{m}^{-2} \mathrm{~s}^{-1}$ in the second meter. Bottom illumination values at $6 \mathrm{~m}$ depth. and underneath a dense Macrocystis pyrifera canopy were about $1.5 \mu \mathrm{E} \mathrm{m}^{-2} \mathrm{~s}^{-1}$; at the same depth outside the canopy they were 10 to $15 \mu \mathrm{E} \mathrm{m} \mathrm{m}^{-2} \mathrm{~s}^{-1}$.

\section{Morphometric relationships and population distribution of $M$. pyrifera}

Holdfast height correlates significantly with its attachment surface (holdfast basal surface area), its total volume and wet weight (Table 1). The mor-

Table 1. Macrocystis pyrifera. Regression equations, correlation coefficients (r) and sample number (N) of 11 relationships between 8 morphometric characters, calculated in plants from Puerto Toro, southern Chile

Holdfast height Holdfast height Holdfast weight Holdfast weight Holdfast volume Number of stipes

Maximum stipe length Maximum stipe length Maximum stipe length Total frond weight Blades per frond - $\mathrm{p}<0.01$
LN Holdfast volume Holdfast basal surface Holdfast height. ${ }^{\text {.75 }}$

Holdfast volume

Holdfast weight

LN Holdfast largest

diameter

Holdfast height

LN Holdfast basal surface

LN Holdfast volume

Holdfast weight ${ }^{1.03}$

Stipe length

\section{r}

$0.77^{\circ}$

$0.78^{\circ}$

$0.92^{\circ}$

$0.93^{\circ}$

$0.92^{\circ}$

0.81 '

$0.92^{\circ}$

$0.87^{\circ}$

$0.88^{\circ}$

$0.98^{\circ}$

$0.94^{\circ}$

\section{N}

110

120

70

70

42

64

74

74

74

43

161 
phometry of erect parts of the plants also have several significant correlations; among these, holdfast height is the best predictor for total plant length while holdfast volume is the best predictor for total frond weight (Table 1). The average number of stipes per plant is $3.14(\mathrm{n}=64)$ within a range of 1 to 15 . The stipe index value (number of stipes $\mathrm{m}^{-2}$ ) is 2.4 .

Different-sized individuals of Macrocystis pyrifera show a predictive pattern of distribution along the belt (Fig. 3). Shorter plants, as indicated by small holdfasts, are found in the shallower end of the belt while increasingly larger holdfasts, and therefore increasingly larger plants, are found in deeper water at increasingly larger distances from the shoreline. The relationship is statistically significant $(p<0.01)$ and the rate of increment of holdfast height is exponential in relation to water depth.

The population of Macrocystis pyrifera found at deeper depths was formed by small individuals with reduced holdfast size (asterisks, Fig. 3). The break

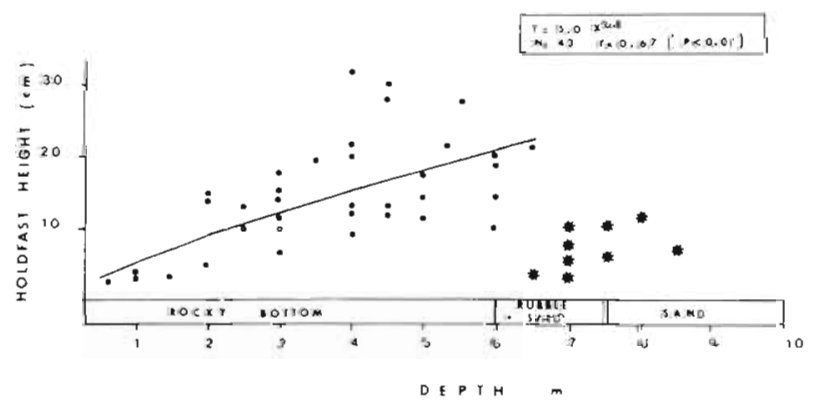

Fig. 3. Macrocystis pyrifera. Changes in holdfasts height with depth. Asterisks: individuals with reduced holdfast sizes occurring on small-sized boulders

seems related to substratum availability; between 1 and $7 \mathrm{~m}$ depth most of the substratum is consolidated rock and boulder. At greater depths the solid substratum is interrupted and replaced by sand with a few small-sized boulders (ca. $15 \mathrm{~cm}$ diameter) which support dwarf $M$. pyrifera plants.

The pattern of distribution of juveniles of Macrocystis pyrifera (plants less than $1 \mathrm{~m}$ height) was inversely correlated with the distribution of adult plants (Fig. 4). Young individuals were in high numbers on both borders, especially at the shore end of the belt. Adult plants (larger than $1 \mathrm{~m}$ ) are most abundant in the central parts of the belt and have decreasing densities towards both margins of the $M$. pyrifera belt.

Inter-plant distances increased significantly as depth increased $(\hat{\mathrm{y}}=40.5+1.86 \mathrm{x}, \mathrm{n}=34, \mathrm{r}=0.58$, $p<0.01)$ and had logarithmic increments as holdfast total volume $(\hat{\mathrm{y}}=-98.0+25.9 \mathrm{LNx} ; \mathrm{n}=74 ; \mathrm{r}=0.70$, $\mathrm{p}<0.01)$ or holdfast height increased $(\hat{\mathrm{Y}}=-27.6+47$ $\left.\mathrm{LNx}_{;} \mathrm{n}=78 ; 4=0.71 ; \mathrm{p}<0.01\right)$. Therefore, inter-plant

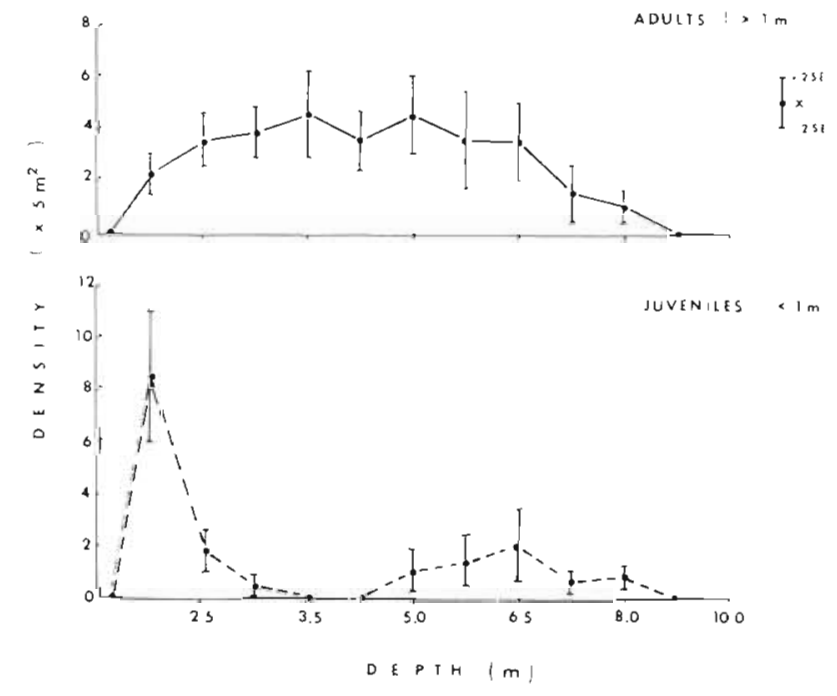

Fig. 4. Macrocystis pyrifera. Distributional pattern of juvenile and adult individuals in the coastal belt of Puerto Toro, Navarino Island

distance has a direct correlation with holdfast size and, through the morphometric relationships established previously, with total plant size. This pattern of correlation, together with the inverse correlation in distribution pattern between adults and juveniles of Macrocystis pyrifera, suggests a density-dependent effect regulating plant sizes within the $M$. pyrifera belt.

\section{Experimental removal of Lessonia vadosa}

A few (3 to 8 ) individuals of Mactocystis pyrifera were found in each of the $3 \times 4 \mathrm{~m}$ experimental plots indicating that $M$. pyrifera could recruit there under the canopy of Lessonia vadosa; however individuals of M. pyrifera averaged only $25 \mathrm{~cm}$ in length (Fig. 5). After removal of all individuals of $M$. pyrifera, 5 new individuals recruited by May 1980 (Plot C, Fig. 5). Nevertheless, in the plots with removal of $L$. vadosa (Plots A and B), M. pyrifera showed increased recruitment and growth. In Plot $\mathrm{A}$, the number of $M$. pyrifera individuals in the $12 \mathrm{~m}^{2}$ surface increased from 8 to 24 , while in Plot B, 32 newly settled plants were found in May 1980. In both cases $M$. pyrifera growth rates (measured as differences in thallus length) were significantly higher than in the plots with the canopy of $L$. vadosa present. In the plot with no removal, no recruitment of $M$. pyrifera was detected. Indeed between November 1979 and May 1980 a decrease in the number of plants was observed apparently due to detachment of the two largest individuals in the plot.

No individuals of Lessonia vadosa recruited into the plots where the adults were removed (Plots A and B) suggesting a limited capacity of dispersion. For May 


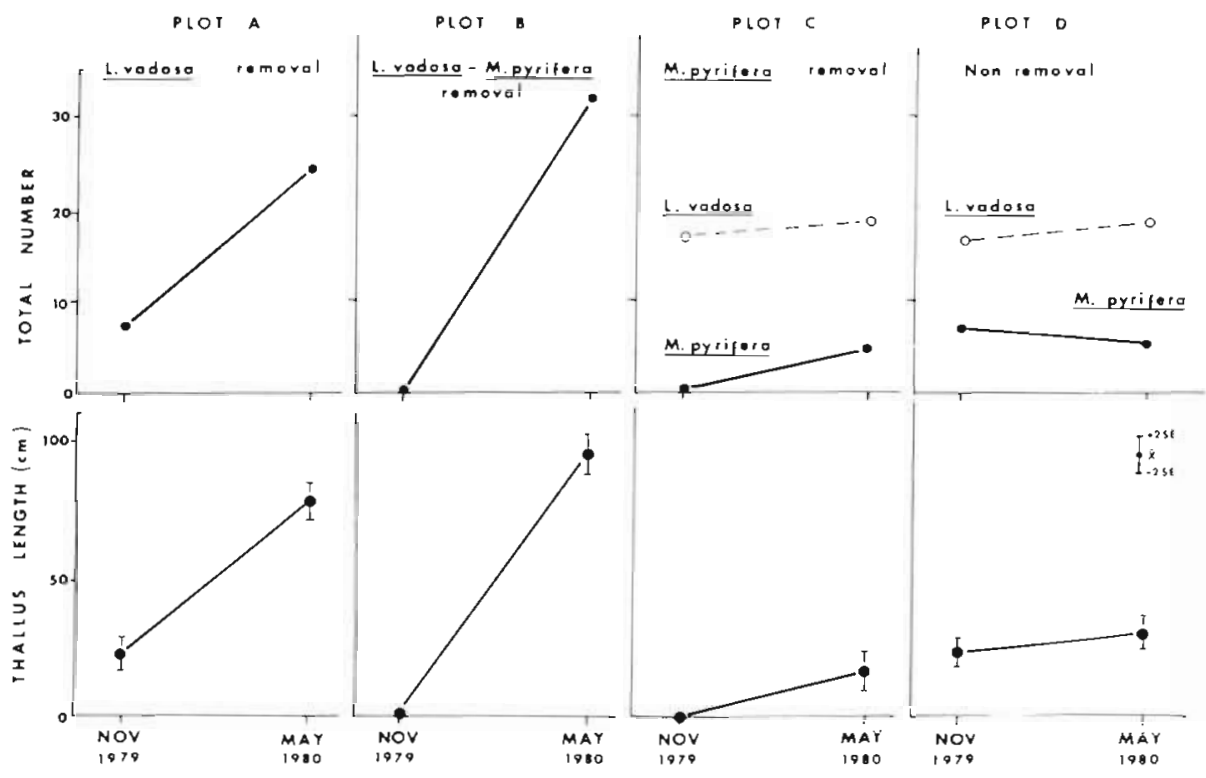

Fig. 5. Macrocystis pyrifera and Lessonia vadosa. Changes in plant density and size after removal experiments

1980, 4 juveniles of $L$. vadosa recruited into Plots $C$ and $\mathrm{D}$ ( 2 in each plot). They were 14 to $16 \mathrm{~cm}$ tall, indicating slower thallus elongation rate than juveniles of Macrocystis pyrifera. Nevertheless, even at a juvenile stage the $L$. vadosa specimens are sturdier plants and seem less affected by storminess than $M$. pyrifera.

\section{Experimental transplanting of $M$. pyrifera at the lower limit of the bed}

Survival capacity and changes in thallus length of the 13 individuals of Macrocystis pyrifera transplanted $50 \mathrm{~m}$ beyond the seaward edge of the bed are shown in Fig. 6. Even though strong individual variation is evident, some trends can be detected. During summer/fall

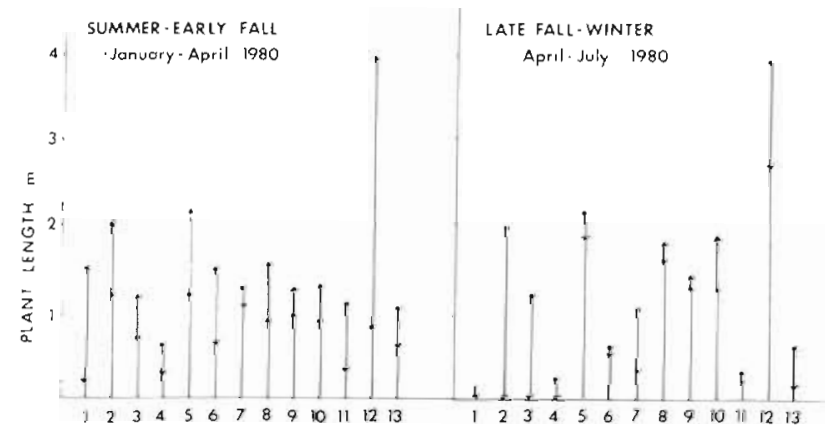

Fig. 6. Macrocystis pyrifera. Growth values in 13 plants attached to a chain and moved seaward of the forest

only 7 individuals increased in thallus length. Five of the 7 plants with decreased thallus length are the nearest neighbours of individuals with thallus elongation (e.g. Plants 11 and 13; 4 and 6; 1) and their thallus reduction may be due to overshadowing by the actively growing adjacent specimens.

During winter, most plants showed reduction in thallus length. Four plants $(1,2,3$ and 4$)$ were lost from the chain, and the remains of other $4(6,7,11$ and 13$)$ were reduced to less than $25 \mathrm{~cm}$. Near the end of the winter (July 1980), only 5 of the 13 experimental plants seemed in good enough conditions to persist through the rest of the winter and to start growing again the next spring. Young sporophytes of Macrocystis pyrifera recruited on the chains along with a variety of filamentous Rhodophyta and Phaeophyta. They were 5 to $20 \mathrm{~cm}$ long by the end of July.

All these results indicate that Macrocystis pyrifera can recruit and extend further into the seaward edge of the bed at some times of the year if hard substratum is available. During spring, summer and early fall there seems to be little abiotic limitations at the seaward edge (other than substratum). A few thalli were able to grow, reaching growth rates above $5 \%$ daily and overshadowing their neighbours. During winter, reduced light intensity coupled with storminess decreases production and allows for the removal of either whole plants or their apical portions. Only a few individuals $(8,9,10)$ were able to grow during this time of the year.

\section{Experimental removal of the Macrocystis pyrifera canopy}

Population studies indicated that inter-plant distances had a direct correlation with holdfast size and total plant size. This pattern of correlation, together with the inverse correlation in distribution pattern between adults and juveniles of Macrocystis pyrifera, 
suggested a density-dependent effect regulating plant sizes within the $M$. pyrifera belt. If this is so, plant distribution pattern and inter-plant distances should be modified by the removal of $M$. pyrifera canopy. Fig. 7 compares the distributions of adults and juveniles of $M$. pyrifera along 2 transects, one of them maintained without canopy for $8 \mathrm{mo}$. In the removal area the number of juveniles between 2 and $5 \mathrm{~m}$ depth (10 to 30 $\mathrm{m}$ from the shallower end of the belt) was $15 / 5 \mathrm{~m}^{-2}$ with

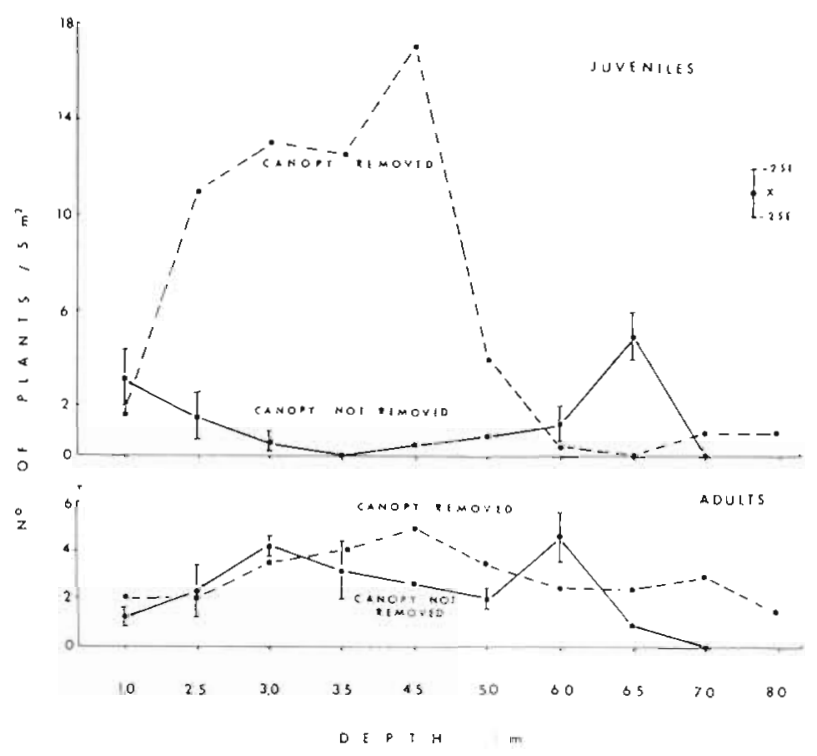

Fig. 7. Macrocystis pyrifera. Changes in distributional patterns of juvenile individuals due to canopy removal

average inter-plant distances of $0.43 \mathrm{~m}$. In the nonremoval area, the number of juveniles was $2 / 5 \mathrm{~m}^{-2}$, and the average inter-plant distance was $0.9 \mathrm{~m}$.

Field observations indicated that the process following juvenile recruitment in the bed is similar to the growth pattern of transplanted plants on the metallic chain. A few individuals show fast growth and over-

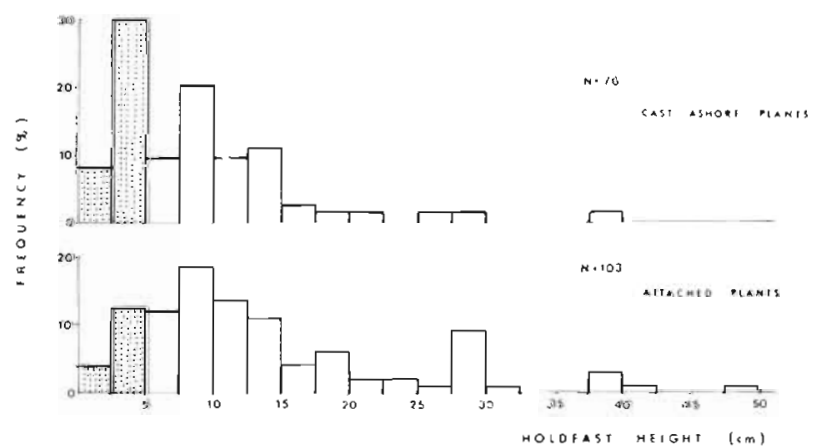

Fig. 8. Macrocystis pyrifera. Comparison of population structure between 76 holdfasts cast ashore and 103 plants attached and measured in the field. Representation of plants with holdfasts less than $5 \mathrm{~cm}$ height (less than $5 \mathrm{~m}$ of total length) are different in both populations (dotted columns) shadow other young individuals in the surroundings. The overshadowed plants apparently are weakened and eventually are removed by water movement. Comparison of the materials normally found cast ashore with a representative sample of the attached plants indicate (Fig. 8) higher numbers of young individuals among the drift materials. This is specially true for plants with holdfasts less than $5 \mathrm{~cm}$ high $\left(\mathrm{x}^{2}\right.$ with Yates correction: 24,63 ; $p<<0.001$ ). Large holdfasts are rare among the plants cast ashore and all them were infested with Phycolimnoria sp., an isopod able to perforate the hapteria. This type of infestation was uncommon among small sized holdfasts and was shown by less than $30 \%$ of the plants with holdfast size of less than $15 \mathrm{~cm}$.

\section{DISCUSSION}

Few studies provide data on morphometric relationships of Macrocystis pyrifera. The highly significant correlations among several morphometric characters found in the plants from the Beagle Channel area point to an harmonic pattern of growth perhaps useful to characterize individuals and population distribution in different geographic areas. It is as yet unknown if similar relationships exist in other $M$. pyrifera populations from southern South America as the only numerical data provided by Barrales and Lobban (1975) refer to stipe indices values. A comparison with pertinent data gathered in populations from southern California (Ghelardi, 1971; North, 1971, 1972) indicates our plants to be significantly smaller in most morphological characters than those specimens. Similarly, the stipe index values of our populations are smaller than the values reported from Chubut.

Field observations and experimental work carried out at Puerto Toro indicate that different factors are important at different parts of the bed in the determination of population structure and distributional patterns of Macrocystis pyrifera. The nearshore edge of the belt appears to be set by interspecific competition with Lessonia vadosa. Experimental results indicate than even though $M$. pyrifera could recruit under $L$. vadosa canopy, densities as well as growth rates are more reduced than in the absence of $L$. vadosa. If $L$. vadosa is removed, the $M$. pyrifera belt could extend 1 to $2 \mathrm{~m}$ further into shallower water. However, these experimental data provide no information to evaluate the factors restricting $L$. vadosa to shallower water. It is possible that $M$. pyrifera could exclude $L$. vadosa from deeper water as Pearse and Hines (1979) found to be the case with Laminaria dentigera and Pterygophora californica in a forest from central California. The overlapping area between $M$. pyrifera and L. vadosa in 
Puerto Toro is close to the mean low water level and is constantly affected by small swells and waves. Perhaps water energy is the factor determining the outcome of the interaction between these 2 species in Puerto Toro. Field observations indicate the sturdier $L$. vadosa plants are able to resist water impact better than small sized $M$. pyrifera individuals. Indeed, in the kelp beds from the South Atlantic studied by Barrales and Lobban (1975), more extensive Lessonia representations were found in kelp beds with higher water energy.

The deeper end of the Macrocystis pyrifera bed in the Puerto Toro area appears primarily set by substratum availability. However, during winter, decreased light intensities and temperatures are perhaps limiting for apical elongation, while increased storminess resulted in increased thallus detachment in transplanting experiments. Field observation further indicate that under extended substratum availability interspecific competition between $M$. pyrifera and Lessonia flavicans, could be expected. In the few areas with solid substratum extending into deeper water, seemingly monospecific stands of $L$. flavicans often seem to limit the seaward extent of $M$. pyrifera sharply.

Plant sizes and distributional patterns inside the Macrocystis pyrifera belt seem largely settled by lightmediated intraspecific competition in a pattern very similar to the one described by Rosenthal et al. (1974) and Pearse and Hines (1979) for the forests of $M$. pyrifera from California. Water movement and surge produce holdfast detachment especially in large individuals infested with Phycolimnoria sp. After removal of large plants recruitment of juveniles takes place. A cohort of young individuals starts growing in the cleared spot. One or several of these sporophytes eventually overshadow other juveniles reducing their production capacities and weakening their attachment surface. Many of these juveniles are eventually removed from the forests of $M$. pyrifera. This explains the high juveniles representation among cast ashore materials and highly significant correlation found between inter-plant distances and plant sizes.

At our study site we found no evidence of the periodic bed destruction described by Barrales and Lobban (1975) for the Macrocystis pyrifera belts of southern Argentina. Indeed a rough correlation of longevity based on growth rates of the faster growing plants in the transplant experiments indicate that the larger individuals in our study site could be well over 4 $y$ old. This age calculation is probably underestimated since it is based on small, fast-growing plants. Extended $M$. pyrifera mortality could nevertheless be produced due to entanglement of drifting or dislodged plants with attached individuals. Entangled plants were observed with some frequency in the study site sometimes including as many as 4 individuals. A simi- lar potential source of mortality for $M$. pyrifera was described by Rosenthal et al. (1974) for the beds of Corona del Mar, California.

A related experimental study in this same bed (Castilla and Moreno, 1981) concluded that sea urchins did not control settlement, growth and final establishment of Macrocystis pyrifera. In a situation very similar to the one described by Rosenthal et al. (1974) for Corona del Mar, California, the sea urchins in Puerto Toro are consuming drifting algae, most of which are senescent $M$. pyrifera fronds. This finding points further to the importance of interspecific competition in the population regulation of $M$. pyrifera and supports the suggestion of Pearse and Hines (1979) indicating that it is not simply the density of sea urchins which determines whether algae will be overgrazed but that the availability of algal litter for food is also important. It has yet to be experimentally tested if drift senescent fronds are preferred by sea urchins over young sporophytes. That possibility, however, would suggest that high frond turnover in these algae may be an adaptation that increases survival capacity of juveniles.

A comparison of the general characteristics of the forests of Macrocystis pyrifera from North and South America have shown many notorious differences (Santelices et al., 1981). Thus, the forests of South America have a simple community structure, reduced species richness in understory vegetation, fish fauna and macro-invertebrate fauna living within and between holdfasts of $M$. pyrifera. In addition, in South America there is an absence of ecological equivalents of the large-sized Laminariales (other than Lessonia spp.), as well as sea-otters which were historically common in the North Pacific. It is interesting to notice, however, that in spite of all the above differences, the $M$. pyrifera populations in the Beagle Channel area have growth and reproduction strategy similar to that known for the North Pacific. The obviously different climatic conditions seemingly have notorious effects only on plant sizes and production rates.

Acknowledgements. This report is part of a comprehensive study on the biology and utilization of Macrocystis pyrifera in southern Chile. The work was financed through a Research Grant agreed on between the Armada de Chile and the Pontificia Universidad Católica de Chile. We thank R. Bravo, G. Casanova, J. C. Castilla, H. Castillo, A. Jullian, A. Larrea, C. Moreno and J. Vásquez for much help in the field, and J. Pearse for critically reading the manuscript. Advice and criticism of 3 reviewers (P. Dayton, J. Estes and D. Reed) improved the manuscript and are acknowledged with gratitude.

\section{LITERATURE CITED}

Aleem, A. A. (1956). Quantitative underwater study of benthic communities inhabiting kelp beds of California. Science, N.Y. 123: 183 
Aleem, A. A. (1973). Ecology of a kelp bed in southern California. Botanica mar. 16: 83-95

Barrales, H. L., Lobban, C. (1975). The comparative ecology of Macrocystis pyrifera with emphasis on the forests of Chubut, Argentina. J. Ecol. 63: 657-677

Bernstein, B. B., Williams, B. E., Mann, K. H. (1981). The role of behavioral responses to predators in modifying urchins (Strongylocentrotus droebachiensis) destructive grazing and seasonal foraging patterns. Mar Biol. 63: 39-49

Breen, P. A., Mann, K. H. (1976a). Changing lobster abundance and the destruction of kelp-beds by sea urchins. Mar. Biol. 34: 137-142

Breen, P. A., Mann, K. H. (1976b). Destructive grazing of kelp by sea urchins in Eastern Canada. J. Fish. Res. Bd Can. 33: $1278-1283$

Castilla, J. C., Moreno, C. A. (1981). Sea urchin and Macrocystis pyrifera: experimental test of their ecological relations in southern Chile. Abstracts International Echinoderm Conference, Tampa Bay, Florida, USA

Chapman, A. R. O. (1981). Stability of sea urchin dominated barren ground following destructive grazing of kelp in St. Margaret's Bay, Eastern Canada. Mar. Biol. 62: 307-311

Dayton, P. K. (1974). Kelp communities of southern South America. Antarct. J. U.S. 9: 22-23

Dayton, P. K., Rosenthal, R. J., Mahan, L. C. (1973). Kelp communities in the Chilean archipelago: $R / V$ Hero cruise 72-5. Antarct. J. U.S. 8: 34-35

Duggins, D. O. (1980). Kelp beds and sea otters: an experimental approach. Ecology 61:447-453

Duggins, D. O. (1981). Sea urchins and kelp: the effects of short term changes in urchin diet. Limnol. Oceangr. 26: 391-394

Estes, I. A., Palmisano, I. F. (1974). Sea otters: their role in structuring nearshore communities. Science, N.Y. 185: $1058-1060$

Foster, M. S. (1975). Regulation of algal community development in a Macrocystis pyrifera forest. Mar. Biol. 32: $331-342$

Ghelardi, R. J. (1971). Species structure of the holdfast community. In: North, W. J. (ed.) The biology of giant kelp beds (Macrocystis) in Califomia. Nova Hedwigia 32: $381-420$

Kühnemann, O. (1970). Algunas consideraciones sobre los bosques de Macrocystis pyrifera. Physis 29: 273-296

Leighton, D. L., Jones, L. G., North, W. J. (1965). Ecological relationships between giant kelp and sea urchins in Southern California. Proc. Int. Seaweed Symp. 5: 141-153
Lowry, L. F., Pearse, J. S. (1973). Abalones and sea urchins in an area inhabited by sea otters. Mar. Biol. 23: 213-219

Mattison, J. E., Trent, J. D., Shanks, A. L., Akin, T. B., Pearse, J. S. (1977). Movement and feeding activity of red sea urchins (Strongylocentrotus franciscanus) adjacent to a kelp forest. Mar. Biol. 39: 25-30

McLean, J. H. (1962). Sublittoral ecology of kelp beds of the open coast area near Carmel, California. Biol. Bull. mar biol. Lab., Woods Hole 122: 95-114

Neushul, M. (1965). Scuba diving studies of the vertical distribution of benthic marine plants. Bot. Gothoburg. 3: $161-176$

North, W. J. (1959). Studies on the influence which water clarity may have on the giant kelp Macracystis pyrifera and its associated organisms. Preprints. Intemational Oceanographic Congress, p. 347-349

North, W. J. (1961). Life span of the fronds of the giant kelp, Macrocystis pyrifera. Nature, Lond. 190: 1214-1215

North, W. J. (1971). Introduction and background. In: North, W. J. (ed.). The biology of giant kelp beds (Macrocystis) in California. Nova Hedwigia 32: 1-96

North, W. J. (1972). Observations on populations of Macrocystis. In: Abbott, I. A., Kurogi, M. (ed.) Contributions to the systematics of benthic marine algae of the North Pacific. Japanese Society of Phycology, Kobe, Japan, p. 75-92

North, W. J., Pearse, J. S. (1970). Sea urchin population explosion in Southern California coastal waters. Science, N.Y 167: 209

Pearse, J. S., Hines, A. H. (1979). Expansion of a central California kelp forest following the mass mortality of sea urchins. Mar. Biol. 51: 83-91

Quast, J. C. (1968). Some physical aspects of the inshore environment, particularly as it affects kelp-bed fishes. In: North, W. J., Hubbs, C. L. (ed.) Utilization of kelp-bed resources in Southern California. Fish. Bull. U.S. 139: 25-34

Rosenthal, R. J., Clarke, W. D., Dayton, P. K. (1974). Ecology and natural history of a stand of giant kelp, Macrocystis pyrifera, off Corona del Mar, California. Fish. Bull. U.S. 72: $670-684$

Santelices, B., Castilla, J. C., Moreno, C. (1981). Macrocystis pyrifera communities from southern South America. Differences with the Northern Pacific. Abstracts XIII International Botanical Congress, Sydney, Australia 